\title{
RESEARCH
}

Research Letter

\section{Warfarin interaction with Matricaria chamomilla}

\section{Robert Segal, Louise Pilote}

\section{ABSTRACT}

No cases have been reported of Matricaria chamomilla potentiating the effects of warfarin. Nevertheless there is a theoretical risk for potentiation, since the herb is thought to be a coumarin constituent. We describe the case of a 70-year-old woman who, while being treated with warfarin, was admitted to hospital with multiple internal hemorrhages after having used chamomile products (tea and body lotion) to soothe upper respiratory tract symptoms. Patient education on the potential risk of taking chamomile products while being treated with warfarin is necessary to avoid such occurrences.

CMAJ 2006;174(9):I28I-2

$\mathrm{T}$ he use of warfarin must be monitored closely by physicians because of its significant and documented risk for potentiation of its anticoagulant effect when used concurrently with other medications ${ }^{1}$ and several alternative therapies, including garlic (Allium sativum) and Ginkgo biloba. ${ }^{2}$ Matricaria chamomilla (German, Hungarian, wild or "genuine" chamomile) is a commonly used natural remedy thought to be beneficial as a sedative, spasmolytic and anti-inflammatory agent. ${ }^{3}$ It is also used to relieve skin maladies such as psoriasis, eczema and acne, and to alleviate fever, bronchitis, cough and the common cold. ${ }^{4}$ Although no evidence of a drug-herb interaction between warfarin and $M$. chamomilla has been documented, there is a theoretical risk because it is thought to be a coumarin constituent. ${ }^{5}$ We report the case of a 70-year-old woman taking warfarin because of her mechanical mitral valve who presented with rectus sheath and retroperitoneal hematomas after she used chamomile products to relieve upper respiratory tract symptoms.

\section{Case}

The 70-year-old woman, who had a medical history that included a mechanical mitral valve placement in 1979 and a previous episode of atrial fibrillation, arrived at the emergency department with a cough, expectoration of yellow sputum 乡ิ and difficulty sleeping. Her medications at the time included warfarin ( $4 \mathrm{mg} 3 \mathrm{~d} / \mathrm{wk}, 6 \mathrm{mg} 4 \mathrm{~d} / \mathrm{wk}$ ), amiodarone, digoxin, synthroid, alendronate, metoprolol and a calcium-vitamin D supplement. Blood was taken for tests; results included hemoglobin $\mathrm{II} 7 \mathrm{~g} / \mathrm{L}$, platelets $193 \times 10^{9} / \mathrm{L}$, creatinine $97 \mathrm{mmol} / \mathrm{L}$ and international normalized ratio (INR) 3.6. Staff diagnosed an infection of the upper respiratory tract; she was discharged home without antibiotics.

Five days later, the patient returned with similar symptoms and feeling weaker. She was dyspneic on exertion and had bilateral pedal edema and ecchymoses in her perineal area, across her lower abdomen and over her left hip. A complete blood count revealed a hemoglobin concentration of $80 \mathrm{~g} / \mathrm{L}$, platelets $218 \times \mathrm{IO}^{9} / \mathrm{L}$, creatinine $82 \mathrm{mmol} / \mathrm{L}$ and an INR recorded as 7.9 (Table I). She received 3 units of packed red blood cells and 2 units of fresh frozen plasma. Abdominal CT revealed a retroperitoneal hematoma in the pelvis, $12 \times 7 \times 6 \mathrm{~cm}$, medial to the left obturator internus muscle, as well as bilateral recti muscle bleeding that measured $4.2 \times 7.7 \mathrm{~cm}$ on the left and $4.7 \times 2.9 \mathrm{~cm}$ on the right.

The patient was admitted to hospital; her coagulation status was maintained with intravenous heparin therapy. The hemorrhages ultimately self-occluded, and the heparin was discontinued when the warfarin dose was adjusted to achieve a stable INR. She was discharged home with a stable hemoglobin concentration and an INR level of 2.5, with follow-up to take place in the cardiology and anticoagulation clinic.

Further questioning revealed that after her initial discharge from the emergency department, the patient attempted to alleviate her pedal edema with a chamomile-based skin lotion, applying a teaspoon-sized dollop to each leg 4-5 times per day. As well, in addition to relieving her chest congestion with a camphor-based lotion, she had attempted to soothe her sore throat with 4-5 cups per day of chamomile tea, prepared by adding water to a teaspoon of dried chamomile leaves. She usually used both chamomile products once or twice per day.

\section{Interpretation}

Despite known interaction between amiodarone and warfarin that potentiates the latter's anticoagulation effects, ${ }^{1}$ the patient

\begin{tabular}{lc}
\hline \multicolumn{2}{l}{$\begin{array}{l}\text { Table 1: Measurements of patient's } \\
\text { international normalized ratio (INR) }\end{array}$} \\
\hline Time & INR \\
\hline 1 mo before presentation & 3.9 \\
5 d before presentation & 3.6 \\
On arrival at hospital & 7.9 \\
At discharge from hospital & 2.5 \\
\hline
\end{tabular}


Box 1: Potential interactions between herbal products and warfarin

Increased risk of bleeding Anticoagulant effects Antiplatelet effects

- Angelica root Bilberry

- Arnica flower Bromelain

- Anise

- Clove

- Asafetida

- Danshen

- Boldo

- Feverfew

- Celery

- Flaxseed oil

- Chamomile

- Garlic

- Dong qua

- Ginger

- Fenugreek

- Ginkgo

- Horse chestnut

- Green tea

- Licorice root

- Meadowsweet

- Lovage root

- Motherwort

- Parsley

- Onion

- Passionflower herb

- Poplar

- Quassia

- Turmeric

- Red clover

- Willow bark

- Rue

- Sweet clover

Decreased risk of bleeding

- Barberry

- Coenzyme $\mathrm{Q}_{10}$

- Ginseng

Other effects

- Oregon grape root

- Bogbean

- Shepherd's purse

- Borage seed oil

- Soy

- Capsicum

- St John's wort

Adapted with permission from Heck AM, DeWitt BA, Lukes AL. Potential interactions between alternative therapies and warfarin. Am J Health-Syst Pharm 2000;57:1221-30.

in this case had been taking both medications concurrently for 3 years without previous incidence of hemorrhage. Moreover, she had not had any episode of hemorrhage since the mitral valve replacement. Her platelet counts were within the normal range at all times, and her INR before the hospital admission recounted here was within the therapeutic range for anticoagulation for a mechanical mitral valve (INR 2.5-3.5). Some new exposure between the 2 emergency department visits must therefore have been responsible for the elevated INR recorded.

According to the patient's daughter, who verifies her medications, there was no possibility of warfarin overdose during that time; consultation with the patient's pharmacist revealed no change in warfarin dosage over the previous II months. Review of the patient's other medications did not reveal any potential interactants with warfarin, and the patient consumed no antiplatelet agents at any time. She denied any change in her diet in the days before her hospital admission. As a result, we ascribe the occurrence of this hemorrhage to the simultaneous and excessive use of chamomile products.

It is highly likely that an herb-drug pharmacodynamic interaction accounted for the increased bleeding observed (Box I). Specifically, the coumarin constituent of chamomile may have worked in synergy with warfarin and resulted in supratherapeutic anticoagulation, which would explain her increased INR. Although a pharmacokinetic interaction cannot be ruled out, we do not believe it was clinically significant in this particular case.
The cytochrome P450 IA2 isoenzyme (CYPIA2) is the most sensitive to inhibition by chamomile. ${ }^{6}$ Only the $R$-enantiomer of warfarin, which exhibits little anticoagulant activity, is metabolized by this isoenzyme, and inhibition of its metabolism does not result in any changes in the INR. ${ }^{7}$ The anticoagulant activity of warfarin resides primarily in the $S$-enantiomer that is metabolized by $\mathrm{CYP}_{2} \mathrm{C} 9$. Chamomile is only a weak inhibitor of this isoenzyme. ${ }^{6}$

To the best of our knowledge, this is the first documented report of an interaction between warfarin and $M$. chamomilla; only a potential for interaction has been noted before. We believe that patients should be educated about the potential risk of using herbal products in general, and chamomile products in particular, while being treated with warfarin.

From the Divisions of General Internal Medicine (Pilote, Segal) and Clinical Epidemiology (Pilote), Montreal General Hospital, McGill University Health Centre, Montréal, Que.

Competing interests: None declared.

Contributors: All authors took part in the drafting and critical revision of the article and have approved the final version to be published.

Acknowledgements: We thank Drs. Mark A. Rabinovitch and Danielle Libersan from the Division of Cardiology, Montreal General Hospital and McGill University Health Centre, for their respective expertise in cardiology and pharmacology.

\section{REFERENCES}

I. Wells P, Holbrook A. Interactions with drugs and food. Ann Intern Med I994; I2I: 676-83.

2. Heck A, DeWitt B, Lukes A. Potential interactions between alternative therapies and warfarin. Am J Health Syst Pharm 2000; 57: I22I-30.

3. O'Hara M, Kieker D, Farrell K, et al. A review of I2 commonly used medicinal herbs. Arch Fam Med I998; (6):523-36.

4. McKesson Health Solutions LLC. Chamomile natural remedy [patient handout]. St. Louis: MD Consult [Elsevier]; 2003.

5. Newall C, Anderson L, Phillipson J. A guide for health-care professionals, herbal medicines. London (UK): Pharmaceutical Press; 1996. p. I32.

6. Ganzera M, Schneider P, Stuppner H. Inhibitory effects of the essential oil chamomile (Matricaria recutita L.) and its major constituents on human cytochrome $\mathrm{P}_{45}$ enzymes. Life Sci 2006;78(8):856-6I (Epub 2005 Aug 31).

7. Kaminsky LS, Zhang Z-Y. Human P450 metabolism of warfarin. Pharmacol Ther I997;73:67-74.

Correspondence to: Dr. Louise Pilote, Divisions of General Internal Medicine and Clinical Epidemiology, Montreal General Hospital, I650 Cedar Ave., Rm. LIo-42I, Montréal QC H3 G IA4; fax 514 934-8293; louise.pilote@mcgill.ca

\section{Editor's take}

- Warfarin, itself derived originally from sweet clover, has anticoagulant properties that resemble those of the coumarin family of substances. No surprise, then, that it may act synergistically with other plant materials that contain coumarins.

Implications for practice: The list of pharmaceuticals that interact is long, and the list of herbal foods and medicines is lengthening. Chamomile's propensity to cause anticoagulation has been known, but no instance of interaction been reported. This case report implies that chamomile should be added to the list of substances that may interact with warfarin. 